\title{
Logoterapia e Teologia: uma hipótese autotranscendente para $o$ aconselhamento pastoral junto às pessoas com tendências suicidas
}

\author{
Logotherapy and Theology: a self-transcendent \\ hypothesis for pastoral counseling for people \\ with suicidal tendencies
}

\section{Logoterapia y Teología: una hipótesis autotrascendente para la consejería pastoral para personas con tendencias suicidas}

\author{
Vardilei Ribeiro da Silva ${ }^{1}$ \\ Blanches de Paula ${ }^{2}$
}

\begin{abstract}
RESUMO
As diferenças sociais, o desemprego, os preconceitos, a violência e tantas outras questões afetam as mais diferentes pessoas e as afetam de maneiras diferentes, tendo em vista a singularidade de cada um. É nessa sociedade complexa que o Aconselhamento Pastoral se apresenta como campo de atuação para pastoras, pastores, leigas e leigos juntamente as pessoas que sofrem e se deparam com o vazio existencial. Apesar da sua relevância, o Aconselhamento Pastoral como uma das áreas da Teologia Prática, carece de maiores subsídios para lidar com o ser humano em crise e em especial aqueles que constantemente são afligidos pelas ideações suicidas. A logoterapia se apresenta, nesse sentido, como área de conhecimento que em sua epistemologia oferece significativas contribuições para a Teologia. O presente artigo se propõe a explicitar as especificidades dessas distintas áreas do conhecimento, bem como apontar as convergências possíveis entre Aconselhamento Pastoral e Logoterapia, tendo em vista a reconhecida relevância que a psicologia já logrou no meio teológico. Por fim, a partir dos princípios logoterapêuticos propomos uma hipótese de Aconselhamento Pastoral para que aqueles que tendem a se despedir da vida pela saída de emergência do suicídio encontrem um real sentido para a vida e, portanto, motivos pelos quais viver.

Palavras chaves: Aconselhamento; vazio existencial; suicídio; logoterapia; teologia.
\end{abstract}

\begin{abstract}
Social differences, unemployment, prejudices, violence and many other issues affect the most different people and affect them in different ways, in view of the uniqueness of each one. It is in this complex society that Pastoral Counseling presents itself as a field of action for pastors, pastors, lay people together with people who suffer and face the existential void.
\end{abstract}

\footnotetext{
Mestrando em Ciências da Religião

2 Professora da Faculdade de Teologia e do Programa de Pós-Graduação em Ciências da Religião na

Universidade Metodista de São Paulo (Umesp)
} 
Despite its relevance, Pastoral Counseling as one of the areas of Practical Theology, lacks greater support to deal with human beings in crisis and especially those who are constantly afflicted by suicidal ideas. In this sense, logotherapy presents itself as an area of knowledge that in its epistemology offers significant contributions to theology. This article aims to explain the specificities of these different areas of knowledge, as well as to point out the possible convergences between Pastoral Counseling and Logotherapy, in view of the recognized relevance that psychology has already achieved in the theological milieu. Finally, based on logotherapeutic principles, we propose a hypothesis of Pastoral Counseling so that those who tend to say goodbye to life for the emergency exit of suicide find a real meaning for life and, therefore, reasons for living.

Keywords: Counseling; existential emptiness; suicide; logotherapy; theology.

\section{RESUMEN}

Las diferencias sociales, el desempleo, los prejuicios, la violencia y muchas otras cuestiones afectan a las personas más diferentes y las afectan de diferentes formas, en vista de la singularidad de cada una. Es en esta sociedad compleja donde la Consejería Pastoral se presenta como un campo de acción para pastores, pastores, laicos junto con personas que sufren y enfrentan el vacío existencial. A pesar de su relevancia, la Consejería Pastoral como una de las áreas de la Teología Práctica, carece de un mayor apoyo para tratar con seres humanos en crisis y especialmente aquellos que están constantemente afligidos por ideas suicidas. En este sentido, la logoterapia se presenta como un área de conocimiento que en su epistemología ofrece importantes aportes a la teología. Este artículo tiene como objetivo explicar las especificidades de estas diferentes áreas de conocimiento, así como señalar las posibles convergencias entre la Consejería Pastoral y la Logoterapia, dada la reconocida relevancia que la psicología ya ha alcanzado en el medio teológico. Finalmente, partiendo de principios logoterapéuticos, proponemos una hipótesis de Consejería Pastoral para que quienes tienden a despedirse de la vida por la salida de emergencia del suicidio encuentren un sentido real a la vida y, por tanto, razones para vivir.

Palabras clave: Asesoramiento; vacuidad existencial; suicidio; logoterapia; teología.

\section{Introdução}

A Logoterapia, terceira escola Vienense de psicoterapia criada por Viktor Frankl, traz como pressuposto que todo o ser humano se realiza existencialmente quando encontra um sentido para a vida. Dito de outro modo entende-se que é no encontrar um sentido para vida que a pessoa encontra a razão para o viver. Nesse sentido é que Frankl parafraseia Nietzsche ao afirmar que "quem tem porque viver suporta quase qualquer como" (FRANKL, 2016, p. 129).

O Aconselhamento Pastoral, uma das áreas da Teologia Prática vem ganhando notoriedade, tendo em vista a conjuntura atual, marcada por crises diversas que assolam o ser humano moderno. Por isso mesmo, essa área tem sido alvo de reflexões e atualizações para que possa efetivamente ajudar aqueles que sofrem.

A reflexão aqui proposta é uma aproximação entre Logoterapia e Aconselhamento Pastoral, uma interdisciplinaridade que promova a saúde integral do aconselhando. Muitas escolas de Teologia já trazem em suas grades curriculares, as disciplinas de Psicologia e Aconselhamento Pastoral, 
nas quais algumas correntes da psicologia contemporânea são apresentadas como ferramentas de subsídio no cuidado pastoral. Acreditamos que dentre as diferentes correntes, a logoterapia carece de especial atenção. Concordamos com Allport ao afirmar que a Logoterapia "é o movimento psicológico mais significativo do nosso tempo" (ALLPORT apud LESLIE, 2013, p. 13).

\section{A especificidade da Logoterapia e do Aconselhamento Pastoral}

Quando pensamos na inter-relação entre Logoterapia e Teologia consideramos o que o próprio Frankl diz a respeito. Na figura abaixo, podemos perceber como Frankl elaborou a relação e campos de atuação da Logoterapia e Teologia no que diz respeito ao trato com o ser humano que vivencia de alguma forma o vazio existencial.

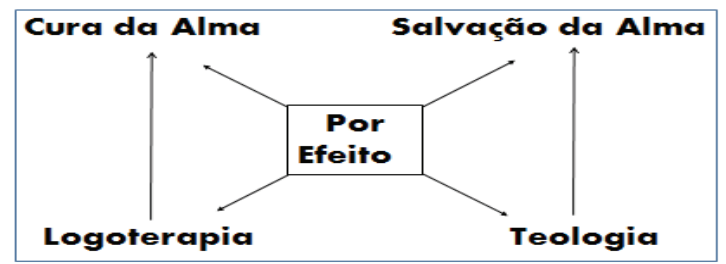

Figura 01 - Adaptado de FRANKL, 2017, p. 74.

O parecer de Frankl é de que Logoterapia e Teologia não se confundem em seus objetivos, apesar de terem em comum o cuidado com o ser humano. No entanto, ele considera a possibilidade de que em seus próprios campos de atuação, tanto uma como outra possam atingir os objetivos que não lhe são próprios.

Entretanto, queremos ressaltar que no campo da Teologia tem-se refletido e adquirido uma visão cada vez mais holística do ser humano, compreendendo-se que o cuidado com o mesmo não se limita ao transcendente, mas de igual modo ao imanente. Nesse sentido queremos enfatizar que no aconselhamento pastoral pode-se não apenas por efeito, mas objetivamente contribuir para a cura da alma, termo utilizado por Frankl para referir-se a psique.

Tendo em vista as demandas do ministério pastoral, para Lotufo Neto é preciso cautela ao se pensar a aproximação entre a atividade pastoral e a psicoterapia, mas apesar desta cautela necessária ele afirma que "há espaço para que o pastor realize psicoterapia. Este seguramente, já realiza a ajuda psicológica informal. Este espaço é bem definido e exclui a doença mental" (LOTUFO NETO, [s.d.], p. 21). Partindo desta premissa, o conselheiro pastoral deve estar ciente da abrangência do seu campo de atuação como de igual modo das delimitações necessárias. 
Portanto, a partir de alguns princípios da Logoterapia queremos refletir sobre a ação pastoral no aconselhamento de modo a estabelecer convergências entre os pressupostos da primeira para a ação da segunda, sem que elas se confundam ou se excluam.

\section{A frustração existencial e o sentido da vida na Logoterapia}

Tendo em vista o recorte proposto, que é discorrer sobre as contribuições da Logoterapia para o Aconselhamento Pastoral junto às pessoas com tendências suicidas, apesar de serem mencionadas, nem todos os importantes fundamentos da Logoterapia serão alvos de profunda reflexão neste texto. Tomamos como ponto de partida, aquilo que Frankl denomina de frustração existencial, para melhor compreensão do fenômeno do suicídio, bem como para melhor atuação dos cuidadores pastorais junto às pessoas que se percebem, frustradas existencialmente.

Para Frankl (2015), a frustração existencial é que possibilita o vazio existencial, aquele sentimento de que nada pode dar novamente sentido a existência. Para o autor, o vazio existencial por sua vez, decorre da perda do instinto e da tradição, consequências da evolução humana.

Para Frankl, o problema decorrente das perdas supracitadas é que o ser humano compromete sua autonomia ao aderir ao conformismo (fazer o que os outros fazem) ou ao totalitarismo (fazer o que querem que façamos). Nesse sentido ele observa:

Quando a consciência é sistemática e metodicamente reprimida e sufocada, o resultado é ou o conformismo ocidental ou o totalitarismo oriental, dependendo se os "valores" excessivamente generalizados pela sociedade são simplesmente oferecidos ou impostos. (FRANKL, 2017, p. 87).

O ser humano tomado pela frustração existencial, poderá, entretanto, valer-se de subterfúgios para mascarar o vazio existencial. Pois conforme Frankl:

Às vezes, a vontade de sentido frustrada é vicariamente compensada por uma vontade de poder [...]. Em outros casos, o lugar da vontade de sentido frustrada é tomado pela vontade de prazer. É por isso que, muitas vezes, a frustração existencial acaba em compensação sexual (FRANKL, 2016, p. 132. Grifo nosso).

De modo geral, Frankl destaca que o vazio existencial "manifesta-se principalmente num estado de tédio" (FRANKL, 2016, p. 131). Para exemplificar, o estado de tédio, Frankl lança mão do termo "neurose dominical" que é uma "espécie de depressão que acomete pessoas que se dão conta da falta 
de conteúdo de suas vidas quando passa o corre-corre da semana atarefada e o vazio dentro delas se torna manifesto" (FRANKL, 2016, p. 132). Essa neurose é muito comum em aposentados, quando na ausência de trabalho perde-se o sentido para a vida.

Conforme Frankl, o vazio existencial pode ser também fomentador daquilo que ele denomina de neurose de massa, ou seja, a depressão/suicídio, agressão e vicio. Dessa tríade que de acordo com Frankl caracteriza a sociedade contemporânea, queremos nos focar na depressão/suicídio (cf. FRANKL apud AQUINO, 2013, p. 69).

Aqueles que já não encontram sentido na vida e tendem a despedir-se dela por meio do suicídio, estão por certo, experimentando a frustração existencial que irá alimentar o vazio que traz sofrimento psíquico. Assim, Frankl afirma que a "depressão, agressão e vicio, não podem ser entendidos se não reconhecermos o vazio existencial subjacente a eles" (FRANKL, 2016, p. 132. Grifo nosso). A morte, nesse sentido, não é obviamente o desejo pelo fim da existência, mas o desejo pelo fim do sofrimento que se torna insuportável.

Entretanto, a Logoterapia irá ressaltar que mesmo em meio ao vazio existencial é possível encontrar um sentido para vida, um sentido autêntico e não mera vontade de poder ou de prazer, que mascaram o vazio existencial, mas não o eliminam.

Para Frankl, cada ser humano ao ser questionado pela vida deve responder responsavelmente pela essência da sua existência. Para a Logoterapia a essência da existência ou o sentido da vida pode ser descoberto de três diferentes formas: "1. Criando um trabalho ou praticando um ato; 2. Experimentando algo ou encontrando alguém; 3. Pela atitude que tomamos em relação ao sofrimento inevitável" (FRANKL, 2016, p. 135). A essas três diferentes formas de encontrar o sentido da vida, Frankl relaciona respectivamente três valores: de criação, de vivência e de atitude.

De que modo os pressupostos da Logoterapia podem contribuir para o Aconselhamento Pastoral junto às pessoas com tendências suicidas? Antes de tentarmos responder a essa questão, queremos, ainda que brevemente, destacar como a prática do aconselhamento no Brasil, tem sido fundamentada em alguns autores específicos, destacando ainda, seus respectivos modelos e métodos, segundo Christoph Schneider-Harpprecht.

\section{Caminhos para o aconselhamento pastoral no Brasil}

Schneider-Harpprecht (2005) nos apresenta de forma sucinta, mas com muita propriedade alguns nomes, cujos modelos e métodos serão descritos 
a seguir. Apresentaremos também as críticas que o referido autor faz a cada um dos modelos apresentados, com exceção do modelo contextual de uma poimênica da libertação, que nos parece ser à perspectiva defendida por ele.

\section{O modelo fundamentalista}

Este modelo foi popularizado no Brasil a partir das concepções de Jay E. Adams, um teólogo norte americano "que critica de maneira radical o uso de qualquer psicologia e chama o aconselhamento para voltar exclusivamente à Bíblia como único fundamento para conduzir a vida do cristão" (SCHNEIDER-HARPPRECHT, 2005, p. 303). O método adotado por Adams "é a conversação que confronta a pessoa com o mal que ela faz [...], responsabiliza pelos seus atos e busca uma nova orientação" (SCHNEIDER-HARPPRECHT, 2005, p. 303). A crítica mais enfática de Schneider-Harpprecht a este modelo de aconselhamento é que o contexto social, histórico e cultural em que residem tanto o aconselhando como o aconselhado não parece ter a devida importância, sendo o aconselhamento centrado fundamentalmente nas verdades bíblicas.

\section{O modelo evangelical de psicologia pastoral}

Neste modelo a psicologia é utilizada como ferramenta para auxiliar no Aconselhamento Pastoral. Neste modelo apriori os pressupostos da Logoterapia, enquanto psicoterapia moderna são bem vindos, no intuito exclusivamente "de ajudar o ser humano e ser mais humano e melhor cristão” (LEÓN apud SCHNEIDER-HARPPRECHT, 2005, p. 305). Dentre os defensores deste modelo, destacamos aqui a figura de Gary Collins, um psicólogo cristão que faz a seguinte crítica àqueles que supostamente rejeitam a psicologia no aconselhamento:

Comprometemos nossa integridade quando rejeitamos abertamente a psicologia, mas a seguir, introduzimos clandestinamente os seus conceitos em nosso aconselhamento algumas vezes ingenuamente e sem sequer perceber o que estamos fazendo (COLLINS apud SCHNEIDER-HARPPRECHT, 2005, p. 304).

A crítica direcionada por Schneider-Harpprecht a este modelo é o risco de se levar a "uma psicologização da fé e a uma teologização da psicologia" (SCHNEIDER-HARPPRECHT, 2005, p. 305), bem como a falta de instrumentos "para um trabalho que inclua o contexto social e político de pobreza e marginalização” (SCHNEIDER-HARPPRECHT, 2005, p. 306). 
Como o próprio nome afirma, neste modelo, preocupa-se com o ser humano holisticamente, em sua integralidade e acredita-se que considerando as seis dimensões ${ }^{3}$ da integralidade humana e aplicando-as a poimênica e aconselhamento pastoral o crescimento rumo a integralidade do ser se torna possível.

A crítica de Schneider-Harpprecht a este modelo é a possível desconsideração da ambiguidade que é a existência humana, marcada obviamente pelo desejo de crescimento, mas que ao mesmo tempo se depara com a ausência de sentido na morte e nas mais diferentes mazelas a que estamos sujeitos enquanto caminhamos em busca de um sentido para a vida (cf. SCHNEIDER-HARPPRECHT, 2005, p. 307).

\section{O modelo contextual de uma poimênica da libertação}

Este modelo traz em seus fundamentos alguns pressupostos da Teologia da Libertação e defende que a Poimênica e o Cuidado Pastoral deveria enfatizar menos uma compreensão individualista de pecado para capacitar as pessoas no discernimento do pecado estrutural que gera a injustiça social, de modo a ajudá-las na luta ativa por libertação (cf. SCHNEIDER-HARPPRECHT, 2005, p. 308).

O método deste modelo varia entre encontros individuais e grupais, mas em ambas as circunstâncias deve-se prevalecer a ênfase de uma perspectiva grupal em que os pecados que trazem sofrimento coletivo sejam discernidos e combatidos.

\section{Uma hipótese autotranscendente de Aconselhamento Pastoral}

Frankl nos fala da autotranscendência como a capacidade que o ser humano tem de olhar para além de si mesmo revelando assim, sua plena humanidade. Nesse sentido, ele afirma:

O que entendo porautotranscendência nada tem a ver com o além; significa que o homem é tanto mais humano quanto mais é ele mesmo, quanto mais ele se supera e se

\footnotetext{
Clinebell diferencia seis dimensões da integralidade humana e deriva das mesmas seis dimensões da poimênica e do aconselhamento pastoral. Elas servem para avivar a mente, revitalizar o corpo, renovar e enriquecer os relacionamentos íntimos de uma pessoa, aprofundar a sua relação com a natureza e a biosfera, crescer em relação as instituições significativas em sua vida, aprofundar e revitalizar seus relacionamentos com Deus nas mais diversas situações durante o ciclo da vida (SCHNEIDER-HARPPRECHT, 2005, p. 306).
} 
esquece a si próprio na dedicação a uma tarefa, a uma coisa ou a um companheiro. Eu não sei se já ocorreu aos senhores que o olho humano também é autotranscendente; sua capacidade de perceber o mundo circundante depende, absolutamente de que ele não seja capaz de se perceber a si mesmo. Quando é que o olho se vê a si mesmo - exceto no espelho? (FRANKL, 1978, p. 56).

É na capacidade de olhar para além de si, ou seja, para sua vontade de poder e prazer, que o ser humano se depara com a realização, com a felicidade enquanto consequência de um motivo e não como busca em si. Na figura abaixo, fica evidente a concepção frankliana da vontade de sentido que se concretiza na autotranscendência.

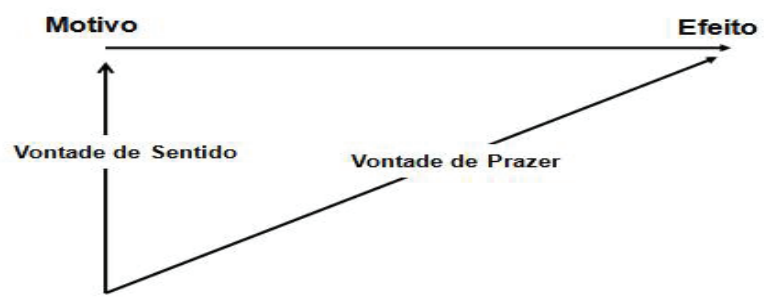

Figura 02 - Adaptado de FRANKL 2015, p. 66.

Para Frankl, a felicidade só pode ser plenamente encontrada quando deixa de ser uma busca em si, e quando o ser humano encontra uma razão, um motivo para ser feliz que está conectado a sua vontade de sentido e não a sua vontade de prazer. Nessa derreflexão (capacidade de deixar de pensar em si e em seu prazer), que o ser humano encontrará sentido nos valores de criação, de vivência e de atitude, que apontam sempre para um motivo e não para um efeito.

É considerando essa conceituação frankliana a respeito da autotranscendência que queremos pensar um modelo de Aconselhamento Pastoral, não exclusivamente, mas especialmente tendo em mente pessoas com tendências suicidas.

Ao nos apropriarmos desta conceituação, fica evidente o nosso distanciamento do modelo fundamentalista descrito acima, pois consideramos a importância da interdisciplinaridade, tendo em vista a complexidade do ser humano. Ao nos apropriarmos desta conceituação nos aproximamos do modelo evangelical de psicologia pastoral, mas queremos tomar o devido cuidado para não incorrermos no risco de psicologização do Aconselhamento Pastoral.

Por fim, fazendo menção aos modelos "holístico de libertação e crescimento" e "contextual de uma poimênica da libertação", ao nos apropriarmos da conceituação frankliana consideramos respectivamente que: 
a) $O$ ser humano pode encontrar sentido em seu sofrimento, ainda que o motivo pelo qual sofre não lhe seja plenamente claro. Frankl afirma que existe um suprassentido que nos permanece oculto, como oculto está para o macaco, o sentido do seu sofrimento ao ser atormentado com injeções dolorosas para obtenção de um soro contra a poliomielite (cf. FRANKL, 2017, p. 105). Assim, consideramos que o sofrimento não pode ser integralmente compreendido e até mesmo aniquilado, mas apesar dele é possível encontrar sentido na vida;

b) Consideramos a importância de um aconselhamento grupal, cuja objetivação seja o discernimento do pecado estrutural, mas ao optarmos pela conceituação frankliana de autotranscendência reconhecemos os limites da Logoterapia, pois esta se foca mais no indivíduo e apesar das conjunturas sociais, econômicas e culturais, não desconsidera a responsabilidade do ser, frente as exigências da vida. Assim Frankl (2016, p. 152) afirma que:

Não se trata de estar livres de fatores condicionantes, mas sim da liberdade de tomar uma posição frente aos condicionamentos. Como eu disse certa vez: "sendo professor em dois campos, neurologia e psiquiatria, sou plenamente consciente de até que ponto o ser humano está sujeito às condições biológicas, psicológicas e sociológicas. Mas além de ser professor nessas duas áreas, sou um sobrevivente de quatro campos - campos de concentração - e como tal também sou testemunha da surpreendente capacidade humana de desafiar e vencer até mesmo as piores condições concebíveis".

Conforme considerações de Schneider-Harpprecht, o "aconselhamento pastoral é uma dimensão da koinonia, assim como o culto, a catequese, a missão e a diaconia" (SCHNEIDER-HARPPRECHT, 2005, p. 292). Logo, no exercício do Aconselhamento Pastoral, o agente pastoral, pastor, pastora ou não, deve atentar-se para as práticas da oração, da leitura bíblica, da exortação, da ação solidária etc. Ressaltamos isso para que apesar dos princípios logoterapêuticos, os aspectos essenciais que diferenciam o agente pastoral do psicólogo não sejam negligenciados.

Considerando as especificidades do Aconselhamento Pastoral em correlação aos princípios logoterapêuticos, destacamos as correlações nos estudos de caso feitos pelo pastor Robert C. Leslie que conciliou alguns eventos bíblicos com os conceitos da Logoterapia já descritos anteriormente, sendo eles o vazio existencial e os valores de criação, vivência e atitude. 
O que Leslie (2013) propõe é que o modo como Jesus lidou com as pessoas ou situações que exigiam posicionamentos decisivos dos envolvidos nas narrativas, convergem com os pressupostos da psicologia contemporânea, no caso, a Logoterapia. Inspirado por Leslie, na tentativa de dialogar com alguns pressupostos logoterapêuticos que podem lançar luz ao Aconselhamento Pastoral, nos propomos aqui, a analisar o comportamento de pelo menos dois personagens bíblicos que desistiram da vida. No entanto, antes de adentrarmos nas especificidades de cada caso, destacamos uma consideração geral feita por Elisabeth Lukas.

Para Lukas, o suicídio é um fenômeno que se prolifera mediante a imitação e para a Logoterapia torna-se importante conscientizar o aconselhando de sua responsabilidade junto aos potenciais familiares enlutados. Segundo a autora, muitas mães depressivas puderam numa renúncia heroica dizer sim a vida e romper com um ciclo de influência de um modelo negativo que desencadearia uma maldição de imitação. Para a autora, para não morrer é preciso ser bom, não apenas para si, mas para algo, para alguém (cf. LUKAS, 1985, p. 188-190). Acrescentamos, é preciso ser responsável!

\section{Judas Iscariotes: a vontade de poder que conduz à frustração existencial ${ }^{4}$}

Os quatro evangelhos descrevem Judas como o discípulo que traiu Jesus. Entretanto, foi apenas no relato do evangelho de Mateus que o suicídio de Judas foi descrito, afirmando que após ter tomado conhecimento da condenação de Jesus, "tocado de remorso, devolveu as trinta moedas de prata aos principais sacerdotes" (Mateus 27.3).

No mesmo evangelho de Mateus 26.14 é descrito o pacto de traição, quando pelo valor das trinta moedas Judas decidiu entregar seu Mestre às autoridades da época, revelando assim o quanto era dominado pela cobiça. No Evangelho segundo João 12.6, quando Judas demonstrou sua indignação com a disposição de Maria em ungir Jesus com um caro perfume, outra faceta do seu caráter foi revelada pelo evangelista ao afirmar que a sua indignação não demonstrava cuidado com os pobres, "mas porque era ladrão e, tendo a bolsa, tirava o que nela se lançava" (João 12.6).

À luz da Logoterapia, a motivação de Judas para trair Jesus está associada a vontade de poder, que denota o complexo de inferioridade, que segundo Adler é próprio de todo o ser humano que se empreenderá na buscapor superioridade (FRANKL, 2016, p. 70). Conforme figura abaixo,

\footnotetext{
4 A menção dos personagens bíblicos dá-se para ilustrar situações em que o suicídio, como é interpretado atualmente, aparece.
} 
para Frankl o poder não se torna um problema quando utilizado como meio para se alcançar um fim, mas sim quando ele se torna um fim em si mesmo.

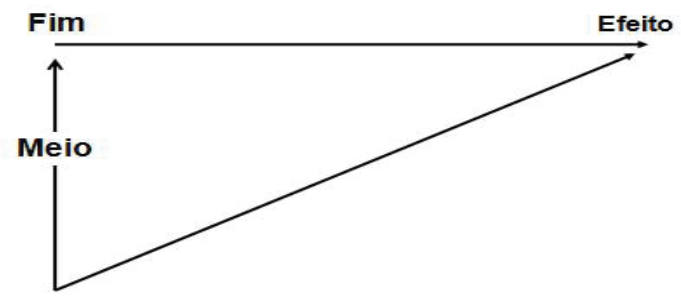

Figura 03 - Adaptado de FRANKL 2015, p. 67.

Para Frankl, quando o poder se torna um fim em si mesmo, fica evidente que a vontade de sentido se encontra frustrada (cf. FRANKL, 2015, p. 67) e esta forma de poder torna-se antagônico ao amor, pois para Frankl (1978, p. 114):

O poder conhece exclusivamente um sentido e um valor subjetivo e relativo, um valor "para mim"; o amor, todavia, vê também o sentido e o valor objetivos e absolutos, o valor "em si". O poder busca a utilidade de uma coisa; o amor, por sua vez, respeita também a dignidade de uma pessoa. O poder faz do indivíduo um egoísta; o amor, em compensação, o torna sensível aos valores.

Em sua busca por superioridade, em seu poder ensimesmado, Judas foi conduzido ao vazio existencial, mediante, enfim, o reconhecimento da culpa. A culpa, uma das constituintes da tríade trágica ${ }^{5}$, poderia, entretanto, ser para Judas ponto de partida para repensar o erro e responsavelmente responder à circunstância da vida reagindo com valores, quer fosse meles criativos, vivenciais ou atitudinais.

Esses valores precisam ser enfatizados no aconselhamento junto a pessoas que estão prestes a desistirem da vida, por enfrentarem a frustração existencial. Não são poucos que dominados pela culpa desesperam-se da vida e ignoram que a culpa assumida, confessada, pode ajudá-los no encontro de novas resoluções de vida, que apontem para o poder como meio de realizar um sentido na vida, sentido que incondicionalmente inclui positivamente o outro.

5 Em resumo, a tese do otimismo trágico, significa que a pessoa é e permanece otimista apesar da tríade trágica, como é chamada em logoterapia a tríade daqueles aspectos da existência humana que podem ser circunscritos por: 1. Dor; 2. Culpa; 3. Morte. Para Frankl, mesmo diante da tríade trágica é possível sempre: 1. Transformar o sofrimento numa conquista e numa realização humana; 2 . Extrair da culpa a oportunidade de mudar a si mesmo para melhor; 3. Fazer da transitoriedade da vida um incentivo para realizar ações responsáveis. (cf. FRANKL, 2016, p.161). 
Outro personagem bíblico que aos olhos de muitos agiu como mártir, mas cuja morte configura suicídio é Sansão. Seduzido pelos encantos das mulheres, pôs-se em diversas confusões com os filisteus, até que em Dalila, uma filisteia, encontrou o ápice destas confusões, por revelar seu segredo e ser subjugado pelos inimigos.

Se não tivesse se entregado aos prazeres imediatos e refletido responsavelmente suas ações o fim de Sansão teria sido outro. Aqui, mais uma vez, chamamos atenção para a dimensão espiritual do ser humano, pois se houvesse ouvido a voz de sua consciência, voz que conforme Frankl transcende o ser, não teria sido conduzido por seus instintos animalescos.

Para Frankl, o ser humano, não é meramente impulsivo, tendo as dimensões "bio-psicoespiritual” em sua constituição. Nesse sentido, quando a dimensão espiritual é suprimida pelas dimensões bio-psíquica é que o ser humano tende a agir por impulso, dando vazão à vontade de prazer. Para Frankl, entretanto, o verdadeiro ser humano é o ser que decide dando vazão à sua dimensão espiritual, onde a vontade de sentido, marcada pela responsabilidade diante da vida é valorizada.

É preciso enfatizar e apontar no aconselhamento que a felicidade se alcança mediante um motivo e não mediante um efeito apriori, mediante a vontade de sentido que sempre aponta para o outro e não mediante a vontade de prazer que sempre apontam para o ser em si.

No caso de Sansão, um segredo não deveria ter sido revelado, e parafraseando Maria von Ebner-Eschenbach (EBNER-ESCHENBACH apud FRANKL, 2017, p. 48), Sansão não foi senhor de sua vontade e tão pouco servo da sua consciência. Para Frankl, ser servo da consciência implica reconhecer a consciência como fenômeno que transcende a mera condição humana (cf. FRANKL, 2017, p. 49).

A busca insaciável pelo prazer de forma inconsequente pode nos conduzir ao vazio existencial ocasionando na pior das hipóteses o desejo de morrer. É necessário que no aconselhamento diante de pessoas com tendências suicidas, os valores espirituais sejam estimulados para que não somente o inconsciente instintivo venha à tona, mas também o inconsciente espiritual que possibilita ouvir com maior nitidez a voz da consciência e servir-la com maior avidez.

\section{Considerações finais}

Dentre os diferentes modelos de aconselhamento pastoral presentes no Brasil, o modelo fundamentalista nos parece ser o preferido nos espaços 
mais conservadores, pois trata-se de um aconselhamento mais diretivo, onde a capacidade do aconselhador em persuadir objetivamente o aconselhando é valorizada. Nesses espaços, a Bíblia é autossuficiente para o aconselhamento e o uso da psicologia é totalmente rejeitado.

Reconhecemos, entretanto, outros espaços eclesiásticos com maior abertura, onde a psicologia tem sido uma importante ferramenta para maior compreensão do ser humano em sua integralidade. Discorremos sobre estes modelos de aconselhamento pastoral que buscam essa importante interação entre psicologia e teologia.

Apresentamos por fim, a Logoterapia, uma psicoterapia que tem sua relevância na atualidade por enfatizar a responsabilidade do aconselhando frente aos dilemas da vida. Acreditamos que a aproximação entre Logoterapia e Aconselhamento Pastoral torna-se possível e necessária na conjuntura atual.

Um Aconselhamento Pastoral que priorize a escuta, que seja não diretivo e que por isso mesmo busque conscientizar o aconselhando de sua responsabilidade, se faz necessário em um contexto marcado pela frustração existencial e consequentemente pelo fenômeno do suicídio como fuga da existência, por vezes, insuportável.

\section{Referências bibliográficas}

AQUINO, Thiago Antonio Avellar de. Logoterapia e análise existencial: uma introdução ao pensamento de Viktor Frankl. São Paulo: Paulus, 2013.

BÍBLIA SAGRADA. Tradução de João Ferreira de Almeida. ARA. Barueri: Sociedade Bíblica do Brasil, 1999.

FRANKL, Viktor. Em busca de Sentido. São Leopoldo: Sinodal, 2016.

FRANKL, Viktor. A Presença ignorada de Deus. São Leopoldo; Petrópolis: Sinodal; Vozes, 2017.

FRANKL, Viktor. O sofrimento de uma vida sem sentido: caminhos para encontrar a razão de viver. São Paulo: É Realizações, 2015.

FRANKL, Viktor. Fundamentos antropológicos da Psicoterapia. Rio de Janeiro: Zahar, 1978.

LESLIE, Robert C. Jesus e a Logoterapia: o ministério de Jesus à luz da psicologia de Viktor Frankl. São Paulo: Paulus, 2013.

LOTUFO NETO, Francisco. O pastor e a psicoterapia. In: TOURNIER; Paul et alii. Psicologia e ajuda pastoral. São Paulo: Nascente Livraria e Editora, [s.d.].

LUKAS, Elisabeth. Assistência logoterapêutica. Petrópolis: Vozes, 1985.

SCHNEIDER-HARPPRECHT, Cristoph. Teologia Prática no contexto da America Latina. São Leopoldo; São Paulo: Sinodal; Aste, 2005, cap. 13, p. 291-318.

Submetido em: 14-9-2020

Aceito em: 21-11-2020 